\title{
Serum procalcitonin level in chronic hemodialytic patients with no evidence of bacterial infection
}

\author{
Koji Ichihara ${ }^{1 *} \mathbb{D}$, Toshiaki Tanaka', Satoshi Takahashi ${ }^{1}$, Masanori Matsukawa², Masahiro Yanase ${ }^{3}$, \\ Hiroshi Kitamura ${ }^{1}$ and Naoya Masumori ${ }^{1}$
}

\begin{abstract}
Background: The baseline levels of serum procalcitonin (PCT) have not been determined in patients with end-stage renal disease needing renal replacement therapy. The purpose of the present study is to verify the reference range of $P C T$ and parameters affecting its value in patients receiving chronic hemodialysis.

Methods: A total of 125 dialytic patients who had no obvious clinical signs of systemic infection were included in this prospective observational study. The PCT level was measured, and its relationships to other clinical and laboratory parameters were evaluated.

Results: The baseline PCT levels of 82 male and 43 female patients were evaluated. Mean baseline PCT level was $0.24 \pm 0.22 \mathrm{ng} / \mathrm{ml}$. Sixteen (12.8\%) patients showed elevated PCT (>0.3 ng/ml) and C-reactive protein (CRP) (>0.3 mg/dl), and 11 (8.8\%) patients showed only abnormal PCT. In 9 patients (7.2\%), PCT levels exceeded $0.5 \mathrm{ng} / \mathrm{ml}$, which is a common cutoff point for sepsis although they had no clinical signs of systemic bacterial infection. The PCT level was statistically correlated with the duration of chronic dialysis, urine volume per day, dialysis time, the serum CRP,

$\beta 2$-microglobulin levels, and normalized dialysis dose.

Conclusions: Most dialysis patients had PCT levels within the reference range of non-dialytic individuals. However, a not negligible number of patients had higher PCT levels than the upper limit of healthy individuals, despite there being no sign of infection. Impairment of renal function and hemodialytic status may affect PCT level.
\end{abstract}

Keywords: Procalcitonin, Renal function, Hemodialysis, Bacterial infection

\section{Background}

Serum procalcitonin (PCT) is a 116-amino acid peptide with a low molecular weight of about $13 \mathrm{kDa}$. The serum PCT level in healthy individuals is under $0.3 \mathrm{ng} / \mathrm{ml}$. In the life-threatening septic condition due to severe bacterial infection, the serum PCT level exceeds $0.5 \mathrm{ng} / \mathrm{ml}$ [1]. On the other hand, the baseline levels of serum PCT have not been determined in patients with chronic kidney disease (CKD), including end-stage renal disease (ESRD) needing renal replacement therapy. Although Herget-Rosenthal et al. [2] utilized the cutoff point of $1.5 \mathrm{ng} / \mathrm{ml}$ for detection of sepsis in hemodialytic patients in their report, their

\footnotetext{
* Correspondence: kichi@sapmed.ac.jp

${ }^{1}$ Department of Urology, Sapporo Medical University School of Medicine, S1, W16, Chuo-ku, Sapporo 060-8543, Japan

Full list of author information is available at the end of the article
}

series mainly included those with systemic infection or sepsis but only a small number of those with no sign of infection. To utilize PCT as a serum marker in ESRD patients for detection or exclusion of sepsis, it is necessary to clarify the baseline level of serum PCT in these patients.

In this study, we measured levels of serum PCT in patients with hemodialysis (HD) and hemodiafiltration (HDF) who had no obvious clinical signs of severe systemic bacterial infection to verify the baseline level. In addition, parameters affecting the baseline PCT level in these patients were also evaluated.

\section{Methods}

Patient inclusion criteria and study design

This non-randomized, non-controlled prospective observational study enrolled 125 adult patients with ESRD 
undergoing chronic intermittent HD or HDF. All patients received dialysis by using a high-flux membrane. Overall, 11 patients had arteriovenous graft for dialysis. There was no patient who had a trouble in the blood access at the time of PCT measurement. All patients were clinically stable, were free from clinical signs of systemic infection, and had no history of surgery during 1 month prior to this study. They had been receiving clinical and laboratorial evaluation routinely to detect the sign of infection every 2 weeks since dialysis induction. Systemic computed tomography was done to rule out active infectious disease if patients had physical and laboratory findings suggestive of infection such as high fever exceeding $38^{\circ} \mathrm{C}$, C-reactive protein (CRP) elevation, or leukocytosis.

We obtained plasma and serum samples from them before dialysis when 2 days had passed from the last dialysis because the timing was reliable to evaluate static state in hemodialytic patients. PCT levels were measured by electrochemiluminescence immunoassay. The results were compared to the normal cutoff level $(0.3 \mathrm{ng} / \mathrm{ml})$ and that of sepsis $(0.5 \mathrm{ng} / \mathrm{ml})$ in normal individuals. In addition, we calculated the variables associated with dialytic efficiency and the nutrition index by using data obtained from blood samples before and after dialysis. The correlations between PCT and these variables were evaluated.

The study protocol was approved by the institutional review board and conducted in accordance with the ethical principles that have their origin in the Declaration of Helsinki (acceptance number 24-93). All participants provided signed informed consent before joining the study.

\section{Statistical analysis}

PCT data was presented as mean ( \pm standard deviation) and median (range) value. The differences in PCT data between groups were examined using Mann-Whitney $U$ test as non-parametric analysis. Correlations were determined by Spearman's rank correlation test as univariate analysis. Correlation coefficient more than \pm 0.8 was defined as strong association in this study. Moreover, multiple linear regression analysis was performed to detect independent parameter that could predict PCT elevation using the variables which showed significant correlation in univariate analysis. However, if each parameter had strong or opposite correlation, the variables which had stronger correlation with PCT were selected to exclude multicollinearity. All statistical tests were two-sided, and statistical significance was defined as a $p$ value of less than 0.05 .

\section{Results}

Patients' characteristics and baseline serum PCT levels The characteristics of 125 patients are shown in Table 1 , and the distribution of serum PCT concentration is shown
Table 1 Patient characteristics

\begin{tabular}{|c|c|c|}
\hline & Mean \pm SD (range) & Number (\%) \\
\hline Age (years) & $66 \pm 11(34-89)$ & \\
\hline Male/female & & $82(65.6) / 43(34.4)$ \\
\hline Duration of dialysis (years) & $6 \pm 5(0-23)$ & \\
\hline Urine volume/day (ml) & $231 \pm 295(0-1000)$ & $64(51.2)$ \\
\hline \multicolumn{3}{|l|}{ Primary disease } \\
\hline DM nephropathy & & $57(45.6)$ \\
\hline Non-DM & & $68(54.4)$ \\
\hline CGN & & $19(15.2)$ \\
\hline IgA nephritis & & $11(8.8)$ \\
\hline Nephrosclerosis & & $9(7.2)$ \\
\hline Others & & $16(12.8)$ \\
\hline Unknown & & $13(10.4)$ \\
\hline \multicolumn{3}{|l|}{ Modality of hemodialysis } \\
\hline $\mathrm{HD} / \mathrm{HDF}$ & & $112(89.6) / 13(10.4)$ \\
\hline \multicolumn{3}{|l|}{ Blood access } \\
\hline Native AVF/AVG & & $114(91.2) / 11(8.8)$ \\
\hline Dialysis time (hours) & $3.9 \pm 0.5(2.3-5.2)$ & \\
\hline \multicolumn{3}{|l|}{$\begin{array}{l}\text { Fluctuation of BP during } \\
\text { dialysis }\end{array}$} \\
\hline Systolic pressure & $44 \pm 23(-38-134)$ & \\
\hline Diastolic pressure & $20 \pm 12(-24-59)$ & \\
\hline Serum creatinine (mg/dl) & $9.5 \pm 2.3(2-15.1)$ & \\
\hline $\begin{array}{l}\text { White blood cell counts } \\
\left(\times 10^{3} / \mu \mathrm{L}\right)\end{array}$ & $5.55 \pm 2.16(2.32-16.9)$ & \\
\hline C-reactive protein (mg/dl) & $0.3 \pm 0.8(0-7.4)$ & \\
\hline Ferritin (ng/ml) & $133 \pm 108(5-796)$ & \\
\hline$\beta 2$ microglobulin (mg/dl) & $25.7 \pm 6.2(8.7-42.7)$ & \\
\hline Intact PTH (pg/ml) & $149 \pm 93(5-496)$ & \\
\hline albumin (g/dl) & $3.3 \pm 0.3(2.2-4.0)$ & \\
\hline $\mathrm{Kt} / \mathrm{N}$ equivalent & $1.23 \pm 0.26(0.41-1.74)$ & \\
\hline nPCR (g/kg/day) & $0.82 \pm 0.17(0.35-1.45)$ & \\
\hline Total body water (ml/kg) & $557 \pm 48.6(428-722)$ & \\
\hline
\end{tabular}

CGN chronic glomerular nephritis, DM diabetes mellitus, HD hemodialysis, HDF hemodiafiltration, AVF arteriovenous fistula, AVG arteriovenous graft, $B P$ blood pressure, $n P C R$ normalized protein catabolic rate

in Fig. 1a. The mean and median baseline serum PCT levels of them were $0.24 \pm 0.22$ and $0.18 \mathrm{ng} / \mathrm{ml}(0.05-1.73)$, respectively. Of them, the PCT levels in 27 patients (21.6\%) were elevated to above $0.3 \mathrm{ng} / \mathrm{ml}$, which is the upper limit of the normal range in healthy individuals. Moreover, 9 patients $(7.2 \%$ ) had baseline serum PCT levels of over $0.5 \mathrm{ng} / \mathrm{ml}$, which is the cutoff point suggestive of sepsis in non-dialytic individuals. The details of them were shown in Table 2.

In this cohort, $20(16 \%)$ patients had leukocytosis $\left(>10^{4} / \mu \mathrm{l}\right)$ and/or elevated CRP $(>0.3 \mathrm{mg} / \mathrm{dl})$ in spite of normal PCT $(\leq 0.3 \mathrm{ng} / \mathrm{ml})$. Furthermore, 16 (12.8 \%) 

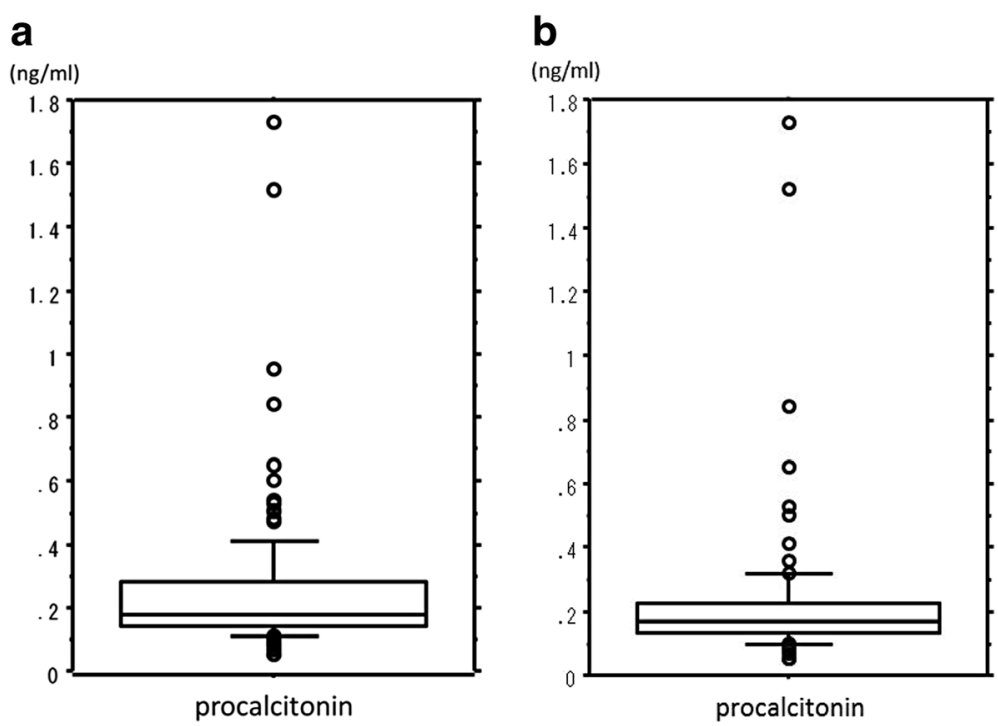

Fig. 1 Distribution of serum procalcitonin level in patients receiving chronic hemodialysis with no evidence of bacterial infection. a Distribution in all 125 patients included in this study. b Distribution in 89 patients with normal C-reactive protein and white blood cell counts. The median is indicated by the horizontal line within the box, and the box shows the interquartile range (IQR). The upper whisker indicates the 75 th percentile + $1.5 \times$ IQR. The lower whiskers indicate the 25th percentile $-1.5 \times$ IQR and upper w. Circles represent outliers extending more than 1.5 box lengths from the box edge

patients showed both elevated PCT and CRP. These patients had potentially localized or latent infectious disease, although other clinical examinations and clinical courses did not suggest such status. Therefore, the distribution of PCT levels in the remaining 89 patients after excluding those with leukocytosis and/or elevated CRP is shown in Fig. 1b. The mean and median baseline serum PCT levels of them were $0.23 \pm 0.25$ and $0.17 \mathrm{ng} / \mathrm{ml}(0.05-1.73)$, respectively. Also among these patients, $5.6 \%$ had baseline serum PCT levels of over $0.5 \mathrm{ng} / \mathrm{ml}$.

All the nine patients with PCT over $0.5 \mathrm{ng} / \mathrm{ml}$ received further evaluations, including physical examination, abdominal computed tomography, chest X-ray, and/or blood culture, to detect the focus of bacterial infection. However, obvious infectious disease could not be detected. Reconfirmation of PCT was performed at more than 12 months after the initial examination in only four cases (Nos (Numbers) 2, 3, 5, and 6 in this cohort, whose PCT levels were $0.47,0.44,0.20$, and $0.61 \mathrm{ng} / \mathrm{ml}$, respectively), whereas the remaining patients were lost to follow-up or died of cerebrovascular disease.

\section{The variables correlated with PCT}

The relationships between variables and PCT are examined by Mann-Whitney $U$ test and Spearman's rank correlation test in 125 patients and shown in Table 3. The duration of dialysis $(R=0.245, p=0.0073)$, dialysis time $(R=0.281, p=0.0033)$, CRP $(R=0.278, p=0.0022)$, serum

Table 2 Details of the patients with procalcitonin exceeded $0.5 \mathrm{ng} / \mathrm{ml}$

\begin{tabular}{|c|c|c|c|c|c|c|c|c|}
\hline No. & Age & Sex & PCT (ng/ml) & $\mathrm{CRP}(\mathrm{mg} / \mathrm{dl})$ & WBCs $\left(\times 10^{3} / \mu \mathrm{l}\right)$ & Modality of hemodialysis & Duration of hemodialysis (years) & Blood access \\
\hline 1 & 59 & Female & 0.51 & 3.7 & 6.25 & $\mathrm{HD}$ & 7 & AVF \\
\hline 2 & 65 & Male & 0.53 & 0 & 6.9 & $\mathrm{HD}$ & 4 & AVF \\
\hline 3 & 73 & Male & 0.54 & 0.6 & 7.96 & $\mathrm{HDF}$ & 23 & AVF \\
\hline 4 & 84 & Male & 0.6 & 1.6 & 7.62 & $\mathrm{HD}$ & 2 & AVF \\
\hline 5 & 62 & Male & 0.65 & 0.1 & 6.1 & $\mathrm{HD}$ & 5 & AVF \\
\hline 6 & 85 & Male & 0.84 & 0.2 & 3.53 & $\mathrm{HD}$ & 12 & AVF \\
\hline 7 & 77 & Male & 0.95 & 0.6 & 3.5 & $\mathrm{HDF}$ & 4 & AVF \\
\hline 8 & 56 & Female & 1.52 & 0.2 & 6.71 & $\mathrm{HD}$ & 6 & AVG \\
\hline 9 & 58 & Female & 1.73 & 0 & 3.22 & $\mathrm{HD}$ & 5 & AVF \\
\hline
\end{tabular}

PCT procalcitonin, CRP C-reactive protein, WBCs white blood cell counts, HD hemodialysis, HDF hemodiafiltration, AVF arteriovenous fistula, AVG arteriovenous graft 
Table 3 Results of the correlations between procalcitonin (PCT) and the other variables using Mann-Whitney $U$ test and Spearman's rank correlation test in 125 patients

\begin{tabular}{|c|c|c|c|}
\hline Variables (number of Pts) & $\begin{array}{l}\text { PCT mean, median } \\
\text { (range) }(\mathrm{ng} / \mathrm{ml})\end{array}$ & $R$ & $p$ value \\
\hline Sex & & & 0.4397 \\
\hline Male (82) & $0.238,0.185(0.05-0.95)$ & & \\
\hline Female (43) & $0.264,0.170(0.05-1.73)$ & & \\
\hline Primary disease & & & 0.4330 \\
\hline DM nephropathy (57) & $0.222,0.180(0.05-0.84)$ & & \\
\hline Non-DM (68) & $0.268,0.185(0.05-1.73)$ & & \\
\hline Modality of hemodialysis & & & 0.0831 \\
\hline HD (112) & $0.240,0.180(0.05-1.73)$ & & \\
\hline $\operatorname{HDF}(13)$ & $0.308,0.240(0.11-0.95)$ & & \\
\hline Blood access & & & 0.8205 \\
\hline Native AVF (114) & $0.242,0.180(0.05-1.73)$ & & \\
\hline AVG (11) & $0.304,0.190(0.10-1.52)$ & & \\
\hline Age & & 0.071 & 0.4408 \\
\hline Duration of dialysis & & 0.245 & 0.0073 \\
\hline Urine volume/day (64) & & -0.348 & 0.0057 \\
\hline Dialysis time & & 0.281 & 0.0033 \\
\hline \multicolumn{4}{|l|}{$\begin{array}{l}\text { Fluctuation of BP during } \\
\text { dialysis }\end{array}$} \\
\hline Systolic pressure & & 0.048 & 0.5939 \\
\hline Diastolic pressure & & 0.102 & 0.2556 \\
\hline Serum creatinine & & 0.136 & 0.1342 \\
\hline White blood cell counts & & 0.159 & 0.0784 \\
\hline C-reactive protein & & 0.278 & 0.0022 \\
\hline Ferritin & & 0.096 & 0.2933 \\
\hline$\beta 2$ microglobulin & & 0.229 & 0.0112 \\
\hline Intact PTH & & 0.048 & 0.6061 \\
\hline Albumin & & -0.125 & 0.1350 \\
\hline $\mathrm{Kt} / \mathrm{N}$ equivalent & & 0.352 & $<0.0001$ \\
\hline $\mathrm{nPCR}$ & & 0.125 & 0.1685 \\
\hline Total body water volume & & -0.007 & 0.9264 \\
\hline
\end{tabular}

Pts patients, DM diabetes mellitus, HD hemodialysis, HDF hemodiafiltration, $A V F$ arteriovenous fistula, AVG arteriovenous graft, $K t / N$ normalized dialysis dose, $B P$ blood pressure, $n P C R$ normalized protein catabolic rate

$\beta 2$ microglobulin ( $\beta 2 \mathrm{MG})$ level $(R=0.229, p=0.0112)$, and normalized dialysis dose $(\mathrm{Kt} / \mathrm{V})$ equivalent $(\mathrm{Kt} / \mathrm{Ve})$ $(R=0.352, p<0.0001)$ had statistically significant positive correlations with PCT although the importance of association in each variable was weak. In addition, urine volume per day $(R=-0.348, p=0.0057)$ had a significant negative correlation with PCT. On the other hand, primary disease, the type of vascular access, and modality of hemodialysis were not correlated with PCT. Multiple linear regression analysis was performed using parameters which had significant correlation in univariate analysis except for dialysis time. Finally, no statistically significant parameter which could predict PCT elevation was determined in this cohort.

As subanalysis, we also evaluated the correlation in 89 patients with normal CRP and without leukocytosis (Table 4$)$. The duration of dialysis $(R=0.301, p=0.0054)$, dialysis time $(R=0.406, p=0.0002)$, serum creatinine $(R=0.293, p=0.0062)$, and Kt/Ve $(R=0.398, p=0.0002)$ showed statistically significant correlation, but no variable could predict PCT elevation.

Table 4 Results of correlations between procalcitonin (PCT) and the other variables in 89 patients without leukocytosis and elevated CRP

\begin{tabular}{|c|c|c|c|}
\hline Variables (number of Pts) & $\begin{array}{l}\text { PCT mean, median } \\
\text { (range) }(\mathrm{ng} / \mathrm{ml})\end{array}$ & $R$ & $p$ value \\
\hline Sex & & & 0.6660 \\
\hline Male (59) & $0.210,0.170(0.05-0.84)$ & & \\
\hline Female (30) & $0.267,0.165(0.05-1.73)$ & & \\
\hline Primary disease & & & 0.5464 \\
\hline DM nephropathy (40) & $0.203,0.165(0.05-0.84)$ & & \\
\hline Non-DM (49) & $0.250,0.170(0.05-1.73)$ & & \\
\hline Modality of hemodialysis & & & 0.7601 \\
\hline HD (82) & $0.232,0.170(0.05-1.73)$ & & \\
\hline HDF (7) & $0.191,0.170(0.11-0.31)$ & & \\
\hline Blood access & & & 0.5319 \\
\hline Native AVF (81) & $0.218,0.170(0.05-1.73)$ & & \\
\hline AVG (8) & $0.341,0.195(0.10-1.52)$ & & \\
\hline Age & & -0.038 & 0.7012 \\
\hline Duration of dialysis & & 0.301 & 0.0054 \\
\hline Urine volume/day (45) & & -0.247 & 0.0703 \\
\hline Dialysis time & & 0.406 & 0.0002 \\
\hline \multicolumn{4}{|l|}{$\begin{array}{l}\text { Fluctuation of BP during } \\
\text { dialysis }\end{array}$} \\
\hline Systolic pressure & & 0.114 & 0.2929 \\
\hline Diastolic pressure & & 0.163 & 0.1315 \\
\hline Serum creatinine & & 0.293 & 0.0062 \\
\hline White blood cell counts & & 0.068 & 0.5308 \\
\hline C-reactive protein & & 0.113 & 0.3371 \\
\hline Ferritin & & 0.074 & 0.4956 \\
\hline$\beta 2$ microglobulin & & 0.193 & 0.0728 \\
\hline Intact PTH & & 0.080 & 0.4645 \\
\hline Albumin & & 0.015 & 0.9532 \\
\hline $\mathrm{Kt} / \mathrm{N}$ equivalent & & 0.398 & 0.0002 \\
\hline $\mathrm{nPCR}$ & & 0.109 & 0.3128 \\
\hline Total body water volume & & -0.127 & 0.2263 \\
\hline
\end{tabular}

Pts patients, DM diabetes mellitus, HD hemodialysis, HDF hemodiafiltration, AVF arteriovenous fistula, AVG arteriovenous graft, $K t / N$ normalized dialysis dose, $B P$ blood pressure, $n P C R$ normalized protein catabolic rate 


\section{Discussion}

PCT is accepted widely in real life clinical practice as a marker not only for diagnosis but also for the therapeutic effectiveness of treatment for sepsis due to bacterial infection. However, the static and dynamic statuses of PCT in patients with ESRD have remained unclear, particularly for those receiving HD or HDF. A limited number of reports showed that PCT was a useful diagnostic marker for systemic bacterial infections in patients with renal insufficiency $[3,4]$. It is well known that impaired renal function and the non-physiologic status related to chronic hemodialysis can affect some biochemical and hormonal measurements. To date, an appropriate cutoff point for serum PCT suggesting systemic bacterial infection in ESRD patients has not been determined. Therefore, we think that it is important to investigate the baseline levels of serum PCT in ESRD patients with no evidence of bacterial infection to utilize PCT for ESRD patients in clinical settings. To the best of our knowledge, this study included the largest number of those with ESRD with no evidence of systemic bacterial infection.

In the present study, PCT levels in most ESRD patients receiving chronic hemodialysis were the same as those in healthy individuals. However, 27 of the 125 patients $(21.6 \%)$ had PCT levels exceeding $0.3 \mathrm{ng} / \mathrm{ml}$, including 9 with PCT $>0.5 \mathrm{ng} / \mathrm{ml}$. Two of these 9 patients (nos. 8 and 9) had extremely high PCT levels, despite stable general condition and no abnormal findings in any other examinations. Although ESRD patients with dialysis sometimes lack subjective symptoms, they normally exhibit some objective findings such as high fever, tachycardia, tachypnea, and/or hypotension when suffering from severe infection or sepsis. Therefore, the solitary elevation of PCT is unlikely to mean early detection of infectious disease. Although repeated measurement was done only in 4 patients, 3 of them had the same level as the initial level.

The PCT level can be elevated in patients with renal insufficiency since PCT is a low molecular weight protein that can be filtered by the renal glomerulus and absorbed by the renal tubules [5]. Herget-Rosenthal et al. [6] reported that the PCT level gradually increased according to the degree of deterioration in renal function and was influenced by the type of the renal replacement therapy. The baseline levels of PCT in CKD patients at stages I to IV did not differ from those in controls. On the other hand, PCT levels in patients with stage V CKD and peritoneal dialysis (PD) were significantly higher than those in controls and patients with stages I to IV CKD. PCT levels in hemodialytic patients were significantly higher than those in CKD and PD patients in any stage. In general, PD patients tend to have more residual renal function than hemodialytic patients, which may be the reason for the difference of PCT levels between them.
In our study, PCT had positive correlations to the duration of dialysis, dialysis time, $\beta 2 \mathrm{MG}$, and $\mathrm{Kt} / \mathrm{Ve}$ and a negative correlation to urine volume. A longer period of hemodialysis, longer dialysis in each session, and higher $\mathrm{Kt} / \mathrm{Ve}$ and decreased urine volume were all associated with dependence on hemodialysis and might be correlated to lesser residual renal function. $\beta 2 \mathrm{MG}$ is low molecular weight protein like PCT and increases in relation to the duration of dialysis. These results supported the relationship between the residual renal function and PCT level. Furthermore, PCT in HDF patients tended to be higher than that in patients with HD, although there was no statistically significant difference. HDF is thought to be appropriate for patients with longer duration of receiving hemodialysis because such patients often have hemodynamic trouble during dialysis or have high $\beta 2 \mathrm{MG}$. Residual renal function tends to be low in these patients, which may explain the higher PCT level in HDF patients. However, the number of HDF patients in the present study was too small, and further study is needed to clarify this situation.

On the other hand, it may be difficult to explain the increase in PCT levels only by the decrease in residual renal function because the amount of PCT produced in thyroidal $\mathrm{C}$ cells is usually extremely small in healthy individuals. Uremia has various influences on the general condition of patients with ESRD [7]. Inflammatory cytokines produced and released by uremia cause chronic inflammation in the whole body. The activation of TNF-alpha, an inflammatory cytokine, is well known to promote PCT production [1]. In addition, uremia promotes the release of acute phase inflammatory reaction substances like CRP. Uremia may potentially induce the production of PCT in hemodialytic patients. In this study, patients with high PCT levels did not always have elevated CRP or leukocytosis. However, there was a correlation between PCT and CRP, production of both of which might be due to inflammatory cytokines induced by uremia. Thus, uremia might also be an explanation for the increase in baseline PCT levels in patients with dialysis, although we did not evaluate the serum levels of inflammatory cytokines in this study. On the other hand, we could not show a statistically significant correlation between WBC and PCT. The function of WBCs can deteriorate due to uremia, malnutrition, and various drugs. Moreover, the number of WBCs in the peripheral blood is changed by dialysis [8]. These factors might affect the discrepancy between the elevation of PCT and WBCs.

The type of dialysis membrane can affect the PCT levels $[2,9]$. Hemodialysis with a high-flux membrane removes $30-80 \%$ of PCT in the serum, and the influence lasts for more than $48 \mathrm{~h}$ although a low-flux membrane does not dialyze PCT. Because the current study did not include patients receiving hemodialysis with a low-flux membrane, the influence of the type of membrane could not be 
assessed. However, we obtained serum samples from all patients before dialysis when 2 days had passed from the last dialysis. Thus, there might be little influence of the dialysis membrane in this study. Further study is needed to clarify the effect of the membrane on the baseline PCT level.

According to the results of a meta-analysis of ESRD patients, the upper limit of the reference range of PCT should be set higher than that in normal individuals [10]. Herget-Rosenthal et al. [2] suggested that $1.5 \mathrm{ng} / \mathrm{ml}$ was an appropriate cutoff point for serum PCT to detect severe infection or sepsis in hemodialytic patients. In the present study, the baseline PCT levels in dialytic patients were almost same as those of healthy individuals. However, $21.6 \%$ of 125 patients and even $12.4 \%$ of 89 patients with normal CRP and white blood cell counts showed PCT more than $0.3 \mathrm{ng} / \mathrm{ml}$. Therefore, actual cutoff value of the baseline PCT in hemodialytic patients might be higher than that in healthy individuals.

Recently, the efficacy of PCT-guided antibiotic therapy for patients with severe sepsis has been investigated [11]. The study recommended that the PCT levels to initiate and discontinue antibiotic therapy be determined differently according to the individual conditions. For utilization of PCT as a guide for antibiotic chemotherapy in HD patients, it is essential to determine the normal range of PCT in the patients. Because the present study provided only preliminary data, further study to determine the normal range is needed.

A major limitation of this study is that we could not absolutely determine that the patients were free of infection including localized infection. PCT is known as a useful marker for systemic bacterial infection or sepsis. At least, systemic bacterial infection and sepsis could be rule out in this series because all of them were healthy and did not have clinical signs such as fever or poor general condition. Therefore, we thought that the results of our study was extremely important finding although further investigations are needed to clarify that serum PCT can be elevated in dialytic patients with localized infection. In addition, the number of patients in this study was relatively small, and larger studies are needed to determine the reference range in dialytic patients.

\section{Conclusions}

Most of the patients with hemodialysis showed normal PCT. However, a not negligible number of them had higher baseline PCT level than those in healthy individuals. In $7.2 \%$ of them, serum PCT exceeded the cutoff point for sepsis in healthy individuals. Impairment of renal function and hemodialytic status may affect the PCT level.

\section{Abbreviations}

CKD: chronic kidney disease; CRP: C-reactive protein; ESRD: end-stage renal disease; HD: hemodialysis; HDF: hemodiafiltration; KtNe: normalized dialysis dose equivalent; PCT: procalcitonin; PD: peritoneal dialysis; $\beta 2 M G$ : $\beta 2$ microglobulin.

\section{Competing interests}

The authors declare that they have no competing interests.

\section{Authors' contributions}

$\mathrm{KI}$ and $\mathrm{TT}$ participated in the design of the study, performed the statistical analysis, and wrote the manuscript. ST, HK, MM, MY, and NM conceived of the study, participated in its design and coordination, and helped to draft the manuscript. All authors read and approved the final manuscript.

\section{Acknowledgements}

We thank Dr. Masahiro Matsuki, Dr. Manabu Igarashi, and the dialysis room staffs of Sunagawa City General Hospital and Takikawa Municipal Hospital for their invaluable cooperation in data collection in this study.

\section{Author details}

'Department of Urology, Sapporo Medical University School of Medicine, S1, W16, Chuo-ku, Sapporo 060-8543, Japan. 'Department of Urology, Takikawa Municipal Hospital, Takikawa, Japan. ${ }^{3}$ Department of Urology, Sunagawa City Medical Center, Sunagawa, Japan.

Received: 15 September 2015 Accepted: 26 January 2016

Published online: 17 March 2016

References

1. Foushee JA, Hope NH, Grace EE. Applying biomarkers to clinical practice: a quide for utilizing procalcitonin assays. J Antimicrob Chemother. 2012;67:2560-9.

2. Herget-Rosenthal S, Marggraf G, Pietruck F, Husing J, Strupat M, Philipp T, et al. Procalcitonin for accurate detection of infection in haemodialysis. Nephrol Dial Transplant. 2001;16:975-9.

3. Steinbach G, Bolke E, Grunert A, Storck M, Orth K. Procalcitonin in patients with acute and chronic renal insufficiency. Wien Klin Wochenschr. 2004;116:849-53.

4. Amour J, Birenbaum A, Langeron O, Le Manach $Y$, Bertrand M, Coriat $P$, et al. Influence of renal dysfunction on the accuracy of procalcitonin for the diagnosis of postoperative infection after vascular surgery. Crit Care Med. 2008;36:1147-54.

5. Meisner M, Lohs T, Huettemann E, Schmidt J, Hueller M, Reinhart K. The plasma elimination rate and urinary secretion of procalcitonin in patients with normal and impaired renal function. Eur J Anaesthesiol. 2001;18:79-87.

6. Herget-Rosenthal S, Klein T, Marggraf G, Hirsch T, Jakob HG, Philipp T, et al. Modulation and source of procalcitonin in reduced renal function and renal replacement therapy. Scand J Immunol. 2005;61:180-6.

7. Bergstrom J, Lindholm B. Malnutrition, cardiac disease, and mortality. Perit Dial Int. 1999;19 Suppl 2:S309-14.

8. Himmelfarb J, Zaoui P, Hakim R. Modulation of granulocyte LAM-1 and MAC-1 during dialysis - a prospective, randomized controlled trial. Kidney Int. 1992:41:388-95.

9. Montagnana M, Lippi G, Tessitore N, Salvagno GL, Danese E, Targher G, et al. Procalcitonin values after dialysis is closely related to type of dialysis membrane. Scand J Clin Lab Invest. 2009;69:703-7.

10. Lu XL, Xiao ZH, Yang MY, Zhu YM. Diagnostic value of serum procalcitonin in patients with chronic renal insufficiency: a systematic review and metaanalysis. Nephrol Dial Transplant. 2013;28:122-9.

11. Meisner M. Update on procalcitonin measurements. Ann Lab Med. 2014;34:263-73

Submit your next manuscript to BioMed Central and we will help you at every step:

- We accept pre-submission inquiries

- Our selector tool helps you to find the most relevant journal

- We provide round the clock customer support

- Convenient online submission

- Thorough peer review

- Inclusion in PubMed and all major indexing services

- Maximum visibility for your research

Submit your manuscript at www.biomedcentral.com/submit 